\title{
Socio-Technical Theory and Knowledge Construction: Towards New Pedagogical Paradigms?
}

\author{
Antonio Cartelli \\ Laboratory for Teaching and Learning Technologies, \\ University of Cassino - Italy, Cassino, Italy
}

cartan@unicas.it

\begin{abstract}
After a short introduction on socio-technical theory, the experiences the author made in the planning and carrying out of web sites and information systems for research and teaching are reported. The results from those experiences are analyzed with a special attention to knowledge development at three different levels: individuals, communities, and organizations (society), and the author's hypotheses for the explanation of the observed phenomena are discussed.

The most relevant results on the effects of ICT on knowledge can be summarized as follows: a) they can improve knowledge construction and induce meaningful learning in students, while contributing in building communities of learners (CoLs) and communities of practice (CoPs), b) they can induce new models for knowledge construction and evolution in special communities and learning organizations, and c) they can contribute in hypothesizing new teaching paradigms (or new pedagogical paradigms more generally).
\end{abstract}

At last a revision of the well known scheme synthesizing the socio-technical approach to organization description (as regards knowledge construction and evolution) is reported and it is applied to the special case of a master course for teachers. The explanation of the effects that the new scheme has on the hypothesized three levels and on the structure of MIS (Management Information System) follows.

Keywords. Socio-technical theory, communities of practice, communities of learners, learning organization, cognitive apprenticeship teaching strategies

\section{Introduction}

Socio-technical theory hypothesizes the presence of two subsystems in every organization or corporate; they are the technical sub-system and the social sub-system.

Material published as part of this publication, either on-line or in print, is copyrighted by the Informing Science Institute. Permission to make digital or paper copy of part or all of these works for personal or classroom use is granted without fee provided that the copies are not made or distributed for profit or commercial advantage AND that copies 1) bear this notice in full and 2) give the full citation on the first page. It is permissible to abstract these works so long as credit is given. To copy in all other cases or to republish or to post on a server or to redistribute to lists requires specific permission and payment of a fee. Contact Publisher@InformingScience.org to request redistribution permission.
Many researchers, notably at the Tavistock Institute in London, while studying the resistance of the work force to innovation and especially to the introduction of technological systems for work automation, suggested that a fit between the two sub-systems was needed for the overcoming of the workers' difficulties and for the achievement of the expected benefits from management. 
The features that scholars hypothesized for the two sub-systems were (Watson, 2004):

- the technical sub-system is much more than the sum of the equipment in the organization; it can be identified with the process responsible for the conversion of system inputs into system outputs. The conversion process must be continuously controlled to be sure that system goals can be achieved;

- the social sub-system, on another hand, is much more than the set of technical control tasks to be performed by people. Technical tasks are combined with individual jobs and with responsibilities assigned to groups. Any analysis and redesign of the social sub-system implies a revision of the jobs and of the corresponding social roles, for the implications they have on the technical sub-system and for the extent to which they enhance or reduce the quality of working life for the individuals and the groups involved in production.

The cornerstone of the socio-technical approach is that the fit is achieved by a design process aiming at the joint optimization of the subsystems; any organizational system maximizes performance only if the interdependency of the subsystems is explicitly recognized. Hence, any design or redesign must seek out the impact each subsystem has on the other, and planning must aim at the achievement of superior results by ensuring that all the subsystems are working in harmony.

The scheme in Figure 1 synthesizes the socio-technical approach and its components (Bostrom \& Heinen, 1977).

Social system Technical system

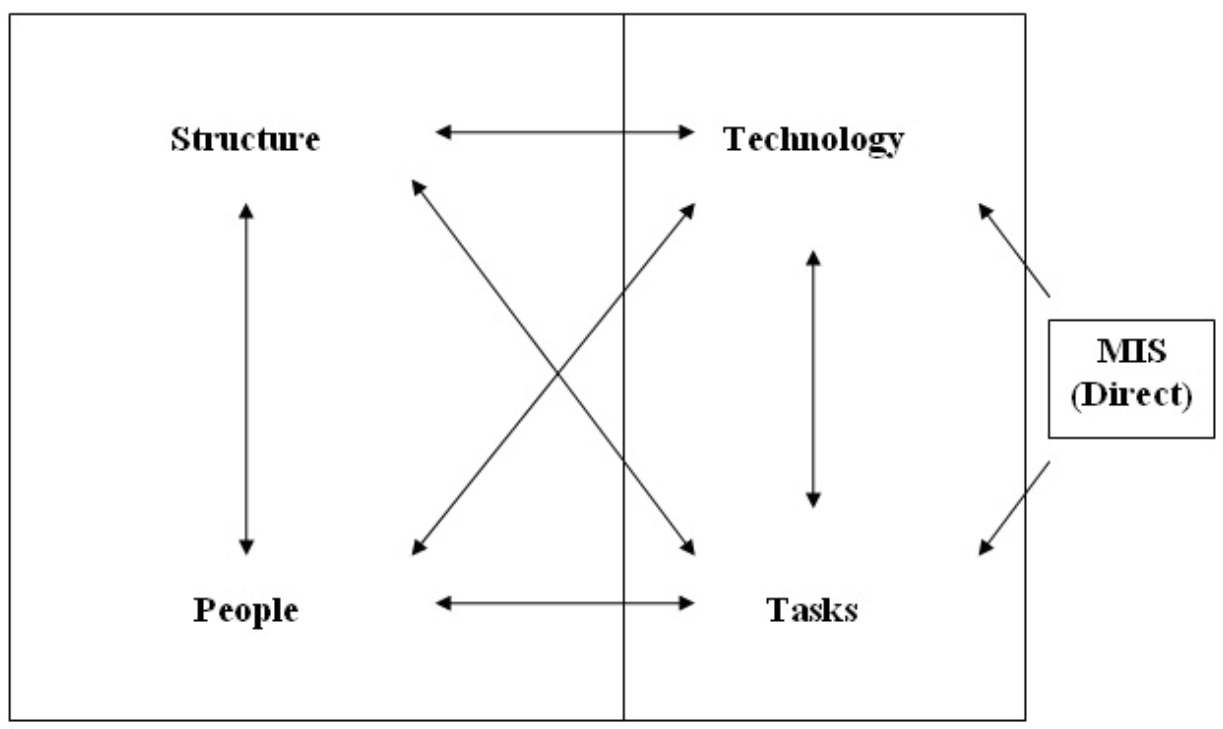

Figure 1 - Socio-technical theory in a draft

More recently, the importance of the consideration of individuals' participation in the life of the organization increased, and a leading role for autonomous and/or semiautonomous groups within the organization and for communities of practices was recognized (Coakes, 2004). Groups and communities of practices (CoPs) arise from special social relationships and are made by individuals, which are motivated to participation by common sets of interests and are willing to develop and share both tacit and explicit knowledge. This is especially true in the knowledge society, where the "socio" appellation in socio-technology takes new meanings and assigns a greater 
value to knowledge, which is socially constructed and developed in the interactions among people.

Today there is common agreement on the enhancement induced into organizations by communities and on the role they play in the fostering of professional development and on organizational learning.

\section{From Case Studies to a New Model for Socio-Technical Approach}

In this section the results of some experiences the author made while cooperating with M. Palma, professor of Latin paleography, are summarized. The experiences reported below are based on special Web sites (mostly information systems), which are used both for research and teaching.

The effects of the systems on students and researchers led the author to compare the results of paleography students with the outcomes many scholars found on communities of learners and, what's more, on communities of practices.

The observed results have been used to support new models for knowledge development also if no superposition with the hypotheses and the ideas reported in the first paragraph could be detected.

The web sites have been planned to manage bibliographical data on medieval manuscripts; some among them also implement the processes usually adopted from researchers to collect bibliographical data. BMB on line (Cartelli \& Palma, 2004), one of the sites falling in the last category, is analyzed here in a greater detail because it is an information system where differently allowed people can store the quotations of Beneventan manuscripts (to let them freely be queried by general users). Persons entrusted with the task of collecting the quotations of Beneventan manuscripts are grouped into three categories:

1. contributors, who can access a special web area where they can write, modify and delete the bibliographical data coming from the printed matters the scientific administrators assigned to them;

2. scientific administrators, who can manage all data and write, modify, and certify bibliographical materials; this last operation being done only once because certified records cannot be reviewed any more (the same operation makes bibliographical records available to general users);

3. the system administrator, who is allowed all operations including the modification or deletion of certified data.

The access to certified bibliographical materials is possible to general users according to different query pages: a) by author's name, b) by manuscript, c) by contributor, d) by one or more words or part of them concerning title, location, or bibliographical abstract of a given publication.

It has to be noted that implemented within the system are also: 1) a closed communication subsystem made by an electronic blackboard, letting contributors and scientific administrators interested in the collection of bibliographical data exchange messages and texts among themselves, 2) some special functions, available only to system administrators, for the production of printed versions of the data yearly collected.

Other web sites to be used for paleographical research and teaching were, "Teaching Materials for Paleography", "Women and written culture in the Middle Ages" (Cartelli, Miglio \& Palma, 2001), the "Open Catalog of Manuscripts of the Malatestiana Library" (Cartelli \& Palma, 2002, 2003). 
While looking at the influence that the above systems had on knowledge construction, a special attention was devoted to three different levels of social aggregation for people involved in the experiences: individual, community, and organization/society (notably scientific knowledge) (Cartelli, 2006b). In other words, the hypothesis of the presence of different rules and processes for knowledge construction when subjects, communities, and the whole society are involved in the use of the above systems, guided the analysis of the effects those systems could produce and the following topics were analyzed in a greater detail: 1) the influence that ICT and web technologies had on knowledge development in students when a social constructivist perspective was adopted for teaching (i.e., the observed results were compared with former studies on human learning and with traditional teaching of paleography), 2) the hypothesis of the presence of new elements in the processes of knowledge construction and evolution within communities of practices and learning organizations, 3 ) the proposal of new strategies for the construction and representation of knowledge in organizations (scientific knowledge).

\section{The Point of View of Individuals (Paleography's Students and Researchers)}

The effects that web sites and information systems had on students and scholars can be summarized as follows:

1. students attending the course of paleography found very useful the materials in the sites and were easily introduced to the core themes of the discipline and to the main topics of the scientific debate,

2. many students were involved in the description of the manuscripts and in the collection of plates reproducing texts, but they were also invited to produce documents to be published in the sites. Furthermore the number of contributions from scholars all over the world grew with time (they intervened in the debate, proposed documents or contributed in documents' revision),

3. some students were involved in the description of manuscripts in the Malatestiana Library and could access the communication subsystem in the Open Catalogue; i.e., they could dialogue and exchange texts with the subscribers of the newsgroup and contribute in the study of the manuscripts. Malatestiana staff recently reported an increasing number of scholars and students asking for access to the communication subsystem in the Open Catalogue and a growing number of reports and discussions concerning the manuscripts in the library,

4. many students, after having attended the basic courses on cataloguing, were asked to become contributors to $B M B$ on line and to produce bibliographical materials. The discussions they had with scientific administrators, professors, and among themselves, the use they made of the electronic blackboard and of the e-mail services for the exchange of messages and, last but not least, the chance of working in small groups on the same problems helped them in acquiring the knowledge and in developing the skills they would need (as paleographers) in their everyday work.

The above events produced effects on students' satisfaction and on their final scores (i.e., performances were now much more positive with respect to the ones from students who were not involved in the same experiences); furthermore they induced deep changes in the way students developed new learning (in what follows the same experiences are analyzed in a constructivist perspective):

1. the suitable use of web technologies (i.e., the information systems underlying the sites), contributed in creating constructivist learning environments (Collins, Seely Brown, \& 
Newman, 1994) and in helping students to develop cognitive apprenticeship strategies (Jonassen, 1994), both very useful for the improvement of students' learning and performances,

2. the careful analysis of students' behaviors (It was possible to observe each student and the whole class, due to the small groups attending the courses.) led to the detection of the features of communities of learners (CoLs) and of fostered communities of learners (FCL) (Brown \& Campione, 1994, 1996); otherwise stated, web technologies, when used to implement special information systems, seem to support and integrate traditional learning strategies and create communities which are not usually detected in those contexts,

3. new skills never observed in traditional paleography courses were detected: a) talent in working in a group, b) easier facing of complex tasks (thanks to the help each student could have from colleagues) and c) raising of the individual's peculiarities within the community. In other words the results from M. Scardamalia and C. Bereiter (1994) on the effects of virtual environments and simulations and the ones from J. Lave and E. Wenger (1991) on Legitimate Peripheral Participation (LPP) were confirmed,

4. new transversal competences were detected: a) better computing skills with respect to those of students attending traditional computing literacy courses, b) meta-cognitive and cognitive apprenticeship strategies.

The main conclusion of the above remarks is that the use of ICT and Web technologies for the creation of special contexts in paleography can help students in building a meaningful learning for that discipline (Varisco, 2002).

\section{The Point of View of Communities of Practice}

The analysis of classes' experiences in a social-constructivist perspective produces remarks not less important than the ones on single students.

From the observation of the classes (the groups of students as a whole) it could be deduced as follows:

1. every group born around one of the above systems, i.e. students, scholars and researchers, can be considered a $\mathrm{CoP}$, because all the features of those communities, as they were defined from E. Wenger (1998, 2004), were detected,

2. the information systems, while implementing the best practices developed from researchers, gave rise to a new kind of knowledge: a community knowledge. (It emerged from the interaction of people with computer-guided processes as the result of a mediation process; it was different from the knowledge of each student or researcher in the community, and it was also different from social-scientific knowledge.),

3. the use of the information systems and the adoption of the corresponding computerguided processes forced students and people involved in their use to respect new times and to follow new steps in their work (The ones of the practices implemented in the information systems.); in such a way the processes' socialization became easier,

4. the bibliographical data collected in the databases expanded the community memory and could be shared among the students in the class or, more generally, among people involved in the experience.

The main conclusions derived from the above remarks are reported below:

1. information systems can make easier the construction of communities of practices and at a least a CoP is built around each one of them, 
2. every system described above implements all or part of the implicit knowledge developed from people working on manuscripts (by means of the processes it manages) and makes easier the socialization of the procedures used in the community (by forcing people to adopt the same procedures); the same system externalizes the tacit knowledge by forcing students/scholars to the use of those procedures. Furthermore the other steps in the SECI (Socialization, Externalization, Combination, Internalization) model, hypothesized by Nonaka and Takeuchi (1995) for knowledge evolution in the community, can be found. Two new statements can be deduced: a) the implementation of the community processes in the information system starts a SECI cycle (before the use of such a system there were no community and no cycle), b) the cycle can be static if an equilibrium is reached at the end of the process, or can be dynamic if at the end of the internalization process the need of new instruments and procedures to be used from the community members arises.

In other words the implementation of practices by means of ICT (web technologies etc.) appears as a different step in the SECI model and can be identified with a new separate element in that model (as reported in Figure 2)

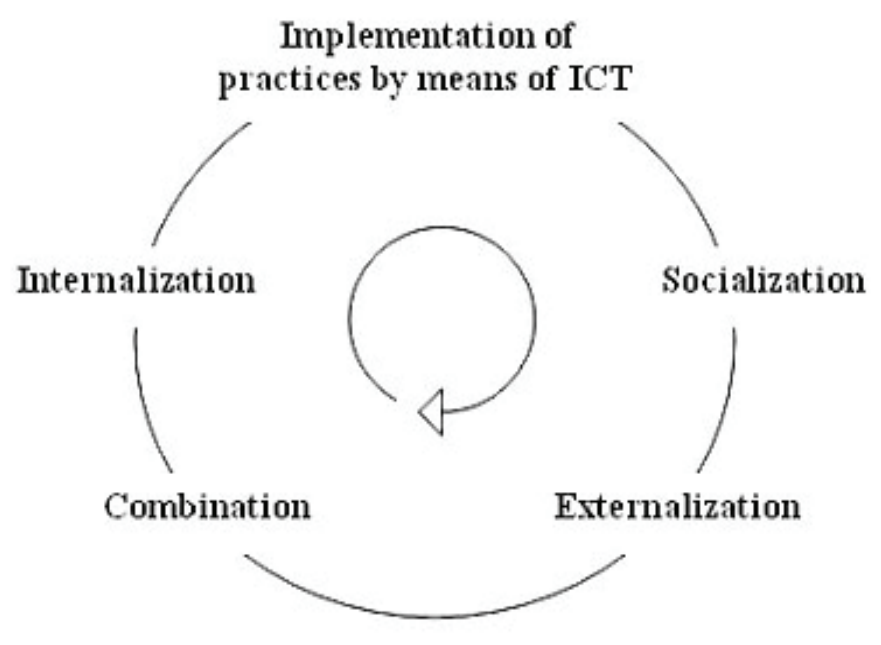

Figure 2 - Revision of the SECI model by addition of a new element

3. the continuous addition of new bibliographical data into any system creates a dynamic shared knowledge which is freely accessible from all community members and which can be defined "community memory" (Trentin, 2004).

\section{The Point of View of Organization/Society}

Due to the generality of this context two different situations have been deeply observed: learning organizations (which cannot be reduced to a simple CoP and usually include many CoPs) and scientific knowledge (which has the special feature of absoluteness and is identical for everyone, it is in fact identified with knowledge in mankind).

As regards learning organizations the following remarks to the experiences described above are reported:

1. the model hypothesized for knowledge evolution in a CoP can be generalized and exported to corporate and organizations (i.e., it is especially true for learning organizations), 
2. the implementation into information systems of the scholars' working processes and procedures gives a new perspective to knowledge management instruments and strategies.

The first remark naturally derives from what has been experimented with almost all the sites. The use of the web sites and of the information systems seems to induce modifications in the structure of the SECI model and introduces the "implementation of practices by means of ICT" as a new element in the cycle, before socialization and after internalization. The main feature of this cycle is its periodicity: the implementation of practices by means of ICT cannot be considered in fact an occasional event or a starting procedure. When a SECI cycle ends new tacit knowledge is developed and new processes are produced so that new software procedures and a revision of the information system are needed. In other words this new element can be considered a stable element for every cycle. Figure 3 reports it in the revised SECI model

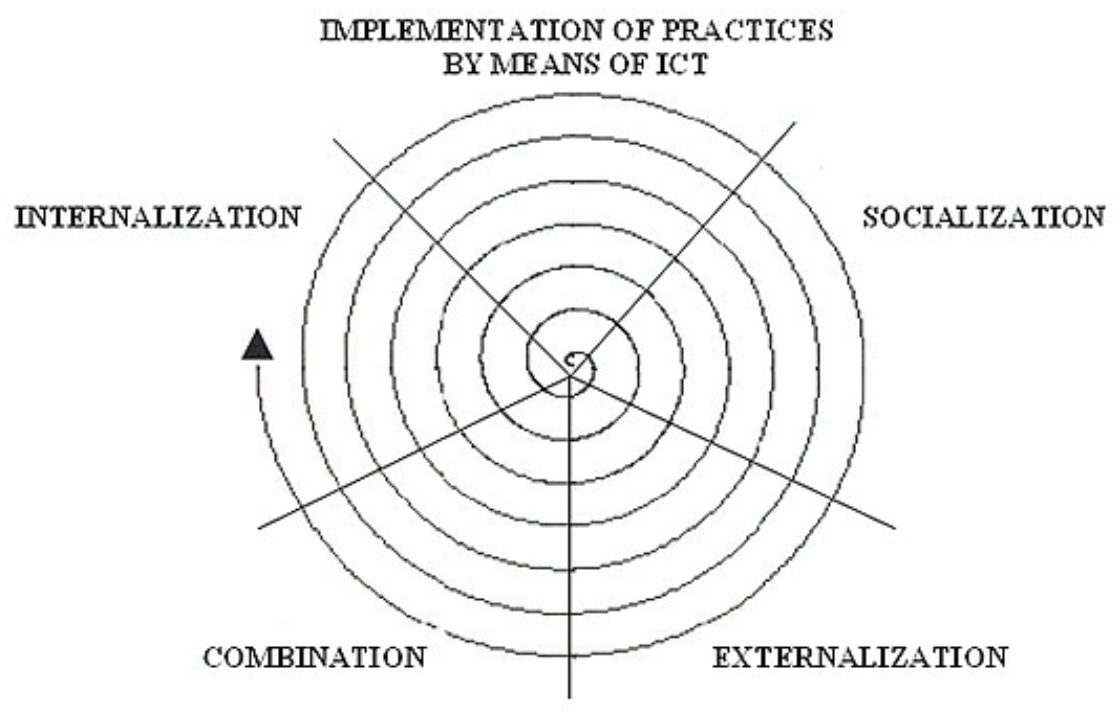

Figure 3 - The hypothesis of new model for knowledge construction and evolution in organizations

The second point naturally follows from the first one because of the implementation of processes and procedures by means of the information systems. Until now knowledge management mostly looked at strategies for capture, storage and retrieval of data and information but didn't concentrate on communities' processes and their implementation; now the analysis of processes and practices and the study of their inclusion in information systems have the same if not more importance for the development of organizational knowledge.

As regards scientific knowledge it has to be noted that:

1. the information stored in the systems is certified by the scientific committees governing the sites (i.e., every group or community produces knowledge with all the features of a science or discipline),

2. people querying the sites interact with the information systems and retrieve information that can be used for building new scientific knowledge (i.e., a new social memory is built by means of those systems and new strategies are needed for the retrieving of information) (Cartelli, 2006a). 


\section{Towards the Hypothesis of a New Model for Socio-Technical Theory}

The consequences of the ideas reported in the above sections on the aggregation levels influencing knowledge construction, on the development of knowledge management strategies, and on the planning of new teaching strategies can be summarized as follows:

a) individual, community, and organization (society) levels confirm their relevant role in knowledge construction and development when special ICT instruments (mostly information systems) contribute in the construction of new learning contexts,

b) the implementation of practices by means of information systems (strongly based on web technologies) introduce a new way of looking at knowledge management in corporate and organizations; knowledge management supports now not only data and information storing and retrieval but also processes' implementation,

c) socio-technical theory hypothesized until now the presence of only two relevant elements in the social sub-system: the subjects and the organization. What role can communities play?

With respect to the scheme reported in Figure 1, where only subjects and society are considered in the social sub-system, the consideration of communities and of the relations they introduce in the social sub-system (and in the way the technical sub-system interact with each of them) appeared relevant, in the author's opinion.

Otherwise stated, whether applying a socio-technical approach in MIS introduction for corporations or organizations, or hypothesizing socio-technical ideas in MIS use in education, the impact of those systems on communities cannot be disregarded, and this new element must be considered in social sub-system together with the better known ones (i.e., subjects and the whole structure).

Social system

Technical system

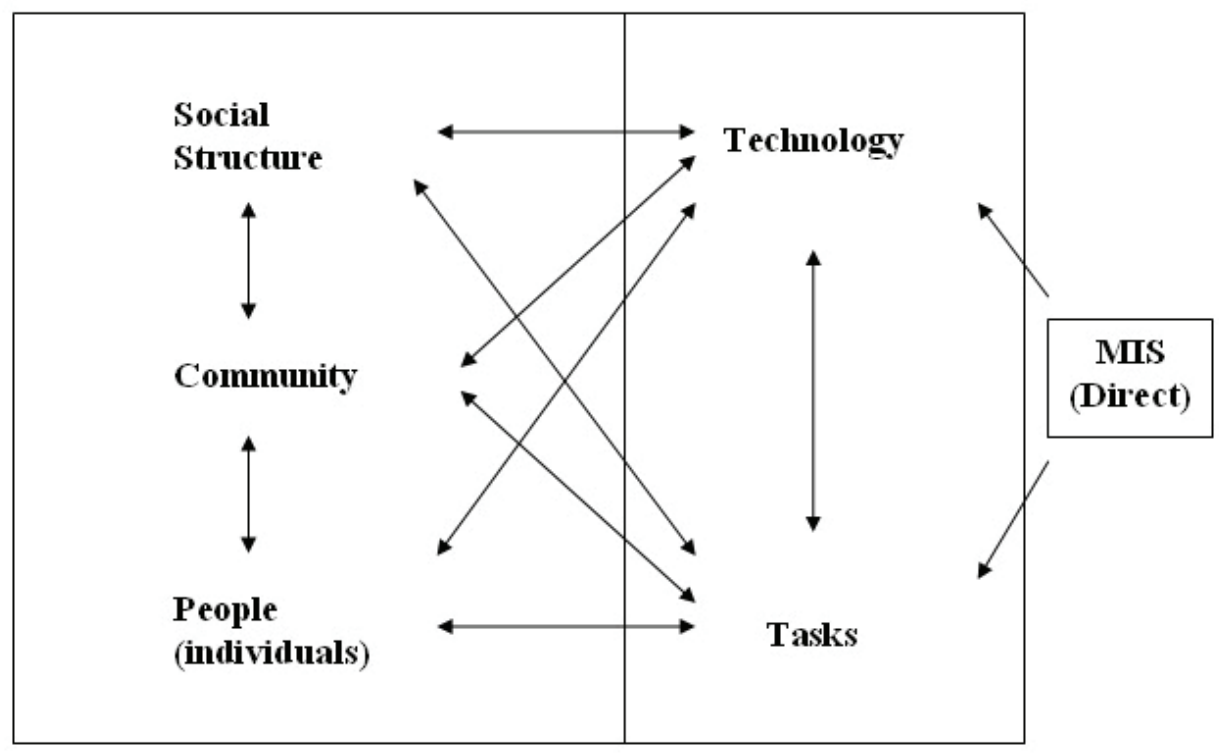

Figure 4 - New model for the socio-technical approach with the introduction of communities 
The new scheme, drafting the structure of the socio-technical approach while considering the relevance of communities, is illustrated in Figure 4, where three elements (individuals, communities and society) are shown in the social sub-system.

The new hypothesis for the structure of socio-technical approach is relevant for the effects it can have on the recognition of the elements involved in the use of MIS and ICT in corporations and organizations (including the school). But it is much more important for the planning of present and future actions involving ICT use and especially IS introduction in everyday contexts.

\section{Conclusion and Future Trends: Can the Socio-Technical Approach be Considered a New Pedagogical Paradigm for ICT in the School?}

The theoretical model reported in the above section for the hypothesis of a new socio technical approach to IS introduction in corporations and organizations is general enough to be applied to different situations. An example can be found in the master course for teachers "Teacher and Tutor in the renewed school" (Docente e tutor nella scuola riformata), which started in academic year 2005-2006 in the University of Cassino, Italy. In this course (managed by the author) two different information systems were adopted and the new hypothesized model for socio-technical approach was used.

First of all it has to be noted that Italian school regulation deeply changed during last two-three years for the introduction of the following elements:

- the definition of the "Educational, cultural and vocational profile" of the student, i.e. the set of things he/she must know (discipline and inter-discipline knowledge) and be able to do (operating and vocational skills) at the end of his/her first school cycle to be the $\mathrm{man} /$ woman and the citizen commonly meant in the society,

- the personalization of the students' curricula (called study programs), coherently with their educational profiles. This process is influenced by a) the organization and coordination of teaching upon national suggestions, b) the acceptance of cultural and educational proposals from families, and c) the integration of school activities with the experiences made available from local institutions (a fraction of the school time must be devoted to these activities),

- the definition of new features/skills for a teacher with special training (called tutormaster) to be charged of the following tasks: a) be responsible for the continuous contact with families and environment, b) have guidance functions for the choice of the activities to be included in the students' personalized study program, c) coordinate educational and didactical activities, d) mind the connections with students' families, e) mind the documentation of the student's instruction route, with the help of other teachers,

- the documentation of the students' career in the "portfolio of personal skills". The portfolio collects notes coming from teachers, parents and (eventually) the same student; these notes are selected among: a) works describing the best skills of the student (made individually or in a group), b) significant school tests, c) remarks on student's learning coming from teachers and families, d) remarks on special works, e) examination papers the student, the family or the school propose for the inclusion in the portfolio (reporting meaningful examples of the student's skill and wish), f) synthetics remarks coming from systematic observations, teachers-family meetings, speech with the student and questionnaires or surveys concerning the student's bents and interests. The portfolio is made of two parts: the former one is devoted to the student's evaluation and assessment, the latter 
one is devoted to guidance; the portfolio must be compiled and brought up to date from the tutor-master teacher.

Due to the described changes there was a great request for training courses from teachers of different school levels and the pedagogical community in the University of Cassino decided to plan a master course, where theoretical and practical topics had to be proposed.

Due to the features of the course target (i.e., teachers employed in schools or people waiting for this kind of employment), the course was blended with presence meetings and distance teachinglearning activities. The distance support to the course was guaranteed from two different instruments/platforms:

a) a first system was used as a CMS (Content Management System) integrated with a CSCLS (Computer Supported Collaborative Learning System). They mostly managed theoretical topics and discussions among students, tutor and professors,

b) the TETIS (Teaching Transparency Information System) platform was used to support the ideas in the socio-technical model.

The TETIS platform in its final stage aims at a more general function, that is at making transparent teaching-learning processes so that each actor of the educational activity can access his/her data and look at the evolution of his/her profile with respect to the planned activities and to the data managed form different people (Cartelli, 2005). The main features of the system are reported below:

a) users accessing the data base have different rights and powers: 1) the user with the least rights can only query the system to obtain general information on schools involved in the project and on the evolution of their educational activities (a general user can only access the school POF - Piano dell'offerta formativa = Formative Offering Plan and its evolution); 2) at an upper level are the students and their families, who can access special web areas (by means of their ID and password) with a menu of the allowed operations, i.e. they can input and modify their general data, can input and modify all information concerning special or extra-school experiences to be included in the portfolio, can look at the evolution of teaching work, at the carrying out of the student's personal study program, at the student's presence at school and at the student's assessment; 3) just in the same way teachers can manage all data concerning teaching planning and evolution (with the assignment of learning units and personal study programs to the students), students' assessment. (It has to be noted that these data become integral part of the portfolio and can be accessed from students and families only after validation from the tutor-master teacher; i.e., after the definitive approval by the class council.); 4) tutor-master, among all teachers, has a special role because validates students' assessment and all data to be included in the portfolio (after the class council); 5) at the top of the access pyramid is the system administrator who can do all the operations allowed to teachers and tutor-masters and can access the verified data to modify or to delete them;

b) students' personal data can be accessed only on a statistical basis from authorized people (like educational researchers or social workers). Class information, like discipline teaching evolution and students general behavior (mean values for evaluation and assessment) can be accessed from students/families in that class. General school information, like the formative offering plan (POF) and its specification in the classes of the school, are available to everyone;

c) when used in everyday teaching the first step in system use is obviously the input of data concerning students, families, teachers, school and learning units; soon after teachers can record data concerning their everyday work and especially students' personal study pro- 
grams, presences and assessments. The tutor-master (after approval of the class council) will validate those data and allowed people could access them for reading.

Figure 5 summarizes the features previously described for the system.

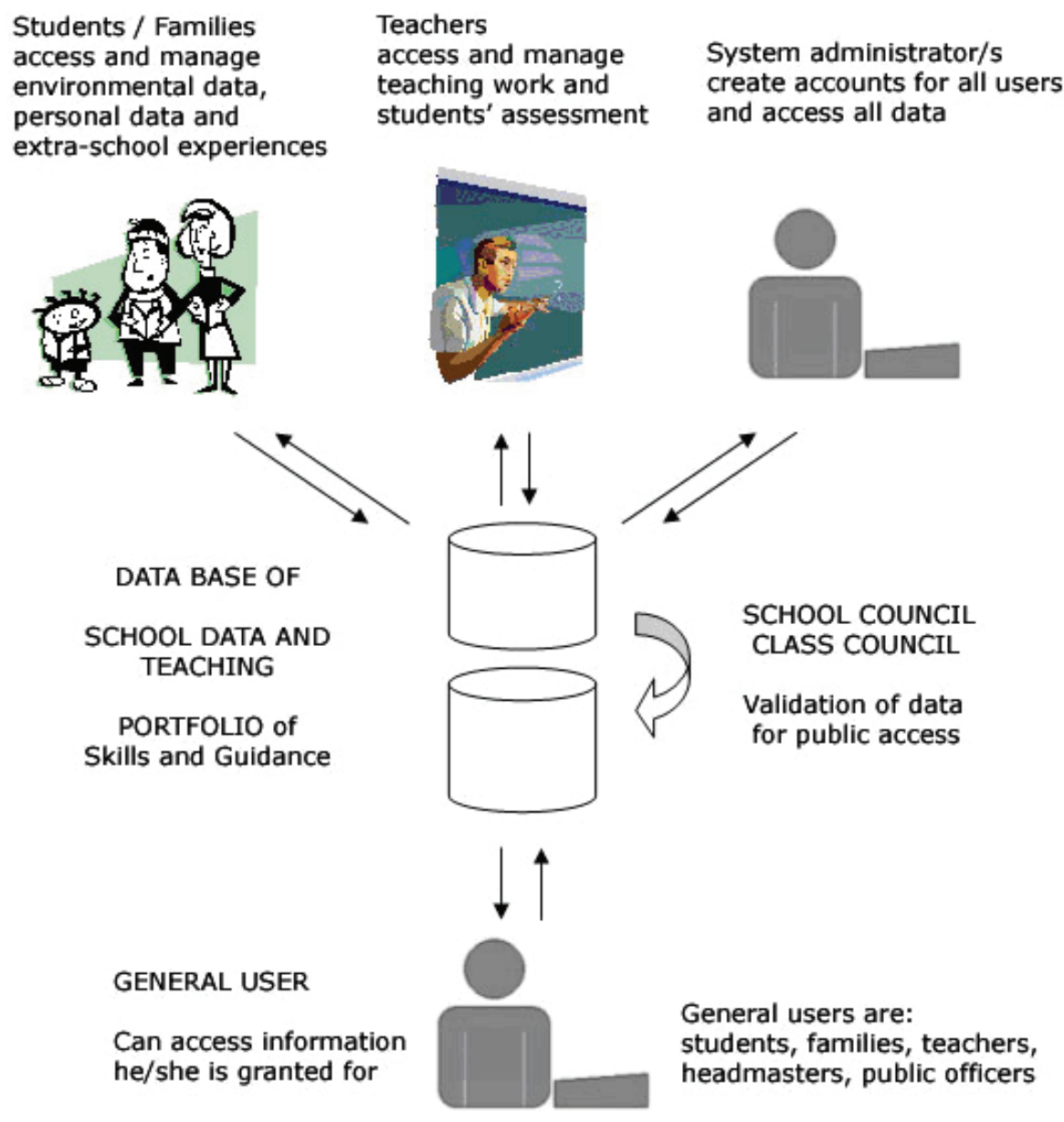

Figure 5 - Data flow in the information system TETIS

The adoption of the new model for the socio-technical approach in the use of the TETIS platform can be easily recognized. The three elements in the social sub-system are now: subjects (students, teachers, researchers etc.), communities (classes, teachers' councils, sometimes integrated by psychologists, pedagogists etc.), and society (all people interacting with the system).

In the master course the TETIS platform could be used partially (due to the lack of reference schools, classes and students) and only teachers' work was implemented. Like in BMB on line, the planning and the carrying out of teaching were implemented, on the contrary a simulation of students answers was simulated.

The scheme in Figure 6 summarizes how teachers' work was implemented in the system. 


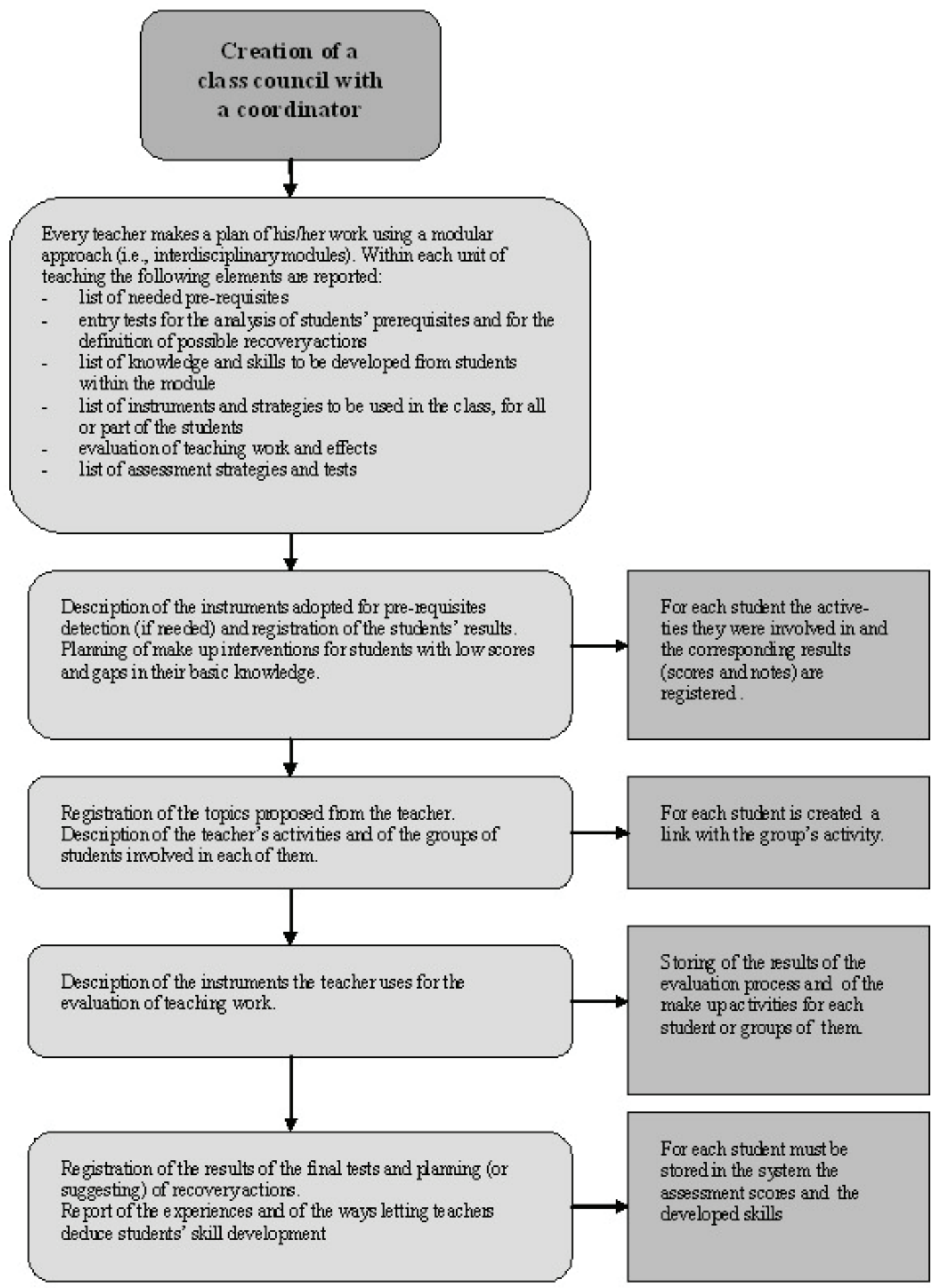

Figure 6 - Steps of teachers' work implemented in TETIS platform

The support to communities of practices electronic blackboards for every class and for every discipline were obtained, which let teachers discuss among themselves in at least two different contexts. 
The extension to students and their families (only simulations could be analyzed) of the access to the platform was obtained by other electronic blackboards letting them interact among themselves and with teachers.

Also, although the experience carried out until now is partial and the system is still under construction, the first comments from teachers are positive and seem to positively evaluate the system. Thus, further experiments seem possible, and next step will lead to the introduction of TETIS platform in real school life.

\section{References}

Bostrom, R. P., \& Heinen, J. S., (1977). MIS problems and failures: A socio-technical perspective. MIS Quarterly, 1 (3).

Brown, A. L., \& Campione, J. (1994). Guided discovery in a community of learners. In K. McGilly (Ed.), Classroom lesson: Integrating cognitive theory and classroom practice (pp. 229-270). Cambridge, MA: MIT Press.

Brown, A. L., \& Campione, J. (1996). Psychological theory and the design of innovative learning environments: On Procedure, principles and systems. In L. Schaube \& R. Glaser (Eds.), Innovation in learning (pp. 289-375). Mahwah, NJ: Erlbaum.

Cartelli, A. (2006a). Semantics, ontologies and information systems in education: Concerns and proposals, Issues in Informing Science and Information Technology, 3, 113-126. Retrieved September 12, 2006 from http://informingscience.org/proceedings/InSITE2006/IISITCart211.pdf

Cartelli, A. (Ed.). (2006b). Teaching in the knowledge society: New skills and instruments for teachers. Hershey, PA: Idea Group Inc.

Cartelli, A., Miglio, L., \& Palma, M. (2001). New technologies and new paradigms in historical research. Informing Science, Special Issue "Widening the Focus", 4(2), 61-66. Available at http://inform.nu/Articles/Vol4/v4n2p061-066.pdf

Cartelli, A. \& Palma, M. (2002). Towards the project of an open catalogue. In E. Cohen \& E. Boyd (Eds.), Proceedings of IS 2002 Informing Science + IT Education Conference, pp. 217-224. Retrieved July 25, 2006 from http://informingscience.org/proceedings/IS2002Proceedings/papers/Carte188Towar.pdf

Cartelli, A., \& Palma, M. (2003). The open catalogue of manuscripts between paleographic research and didactic application. In M. Khosrow-Pour (Ed.), Proceedings of the IRMA 2003 Conference "Information Technology \& Organization: Trends, Issues, Challenges and Solutions", pp. 51-54. Hershey (PA): Idea Group Publishing.

Cartelli, A., \& Palma, M. (2004). BMB on line: An information system for paleographic and didactic research. In M. Khosrow-Pour (Ed.), Proceedings of the IRMA 2004 Conference "Innovation through Information Technology”, pp. 45-47. Hershey (PA): Idea Group Publishing.

Coakes, E. (2004). Knowledge management a primer. Communications of the Association for Information Systems, 14, 406-489.

Collins, A., Seely Brown, J., \& Newman, S. E. (1995). Cognitive apprenticeship: Teaching the craft of reading, writing and mathematics. In C. Pontecorvo, A. M. Ajello, \& C. Zucchermaglio (Eds.), L'apprendistato cognitivo. Per insegnare a leggere, scrivere e far di conto (pp. 181-231). Florence: La Nuova Italia.

Jonassen, D. H. (1994). Thinking technology. Towards a constructivist design model. Educational Technology, 34(4), 34-37.

Lave, J. \& Wenger, E. (1991). Situated learning. Legitimate peripheral participation. New York (NJ): Cambridge University Press.

Nonaka, I. \& Takeuchi, H. (1995). The knowledge-creating company: How Japanese companies create the dynamics of innovation. New York (NJ): Oxford University Press. 
Scardamalia, M., \& Bereiter, C. (1996). Engaging students in a knowledge society. Educational Leadership, 54(3), 6-10.

Trentin, G. (2004). Apprendimento in rete e condivisione delle conoscenze. Milan: Franco Angeli.

Varisco, B. M. (2002). Costruttivismo socio-culturale. Rome: Carocci.

Watson, N. (2004). Background paper on socio-technical theory. Retrieved July 25, 2006 from https://www.sonoma.edu/phpbb/viewtopic.php?p=332\&sid=d04e94067bded6533e607232a556a433

Wenger, E. (1998). Communities of practice: Learning, meaning and identity. New York (NJ): Cambridge University Press.

Wenger, E. (2004). Communities of practice: A brief introduction. Retrieved July 25, 2006 from http://www.ewenger.com/theory/index.htm

\section{Biography}

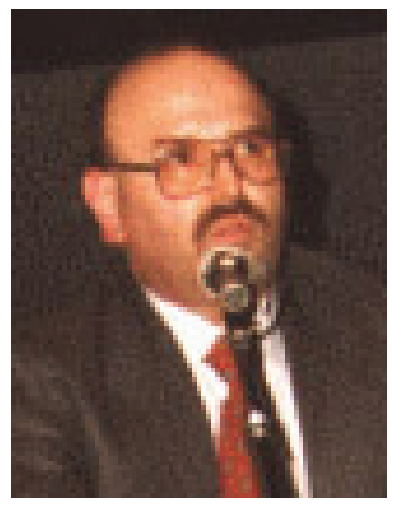

Antonio Cartelli is a researcher in Didactics. He manages the Laboratory for Teaching-Learning Technologies and the Centre for ICT and on line teaching in the Faculty of Humanities at the University of Cassino - Italy. Among his interests are: misconceptions, mental schemes, Information Systems for research and teaching, Web Technologies in teaching research and their everyday application for the improvement of teaching and learning. He is also author of many papers and books concerning the themes he is interested in. 